\title{
THE OPERATIVE CLOSURE OF VENTRICULAR SEPTAL DEFECTS IN CHILDHOOD
}

\author{
W. T. Mustard, M.D. \\ Assistant Professor, University of Toronto. Associate Surgeon, Hospital for Sick Children, Toronto
}

THE successful operative closure of a ventricular septal defect accomplished by Lillehei, Cohen, Warden, Ziegler and Varco (1955) not only awakened the latent interest of internists and pathologists but introduced a new surgical field. First described by Roger in 1879 , the defect was well documented by Abbott in 1932 who correlated the pathology with clinical findings.

\section{Incidence and Natural History}

Ventricular septal defect is the commonest congenital heart lesion in childhood and probably accounts for $20 \%$ of all heart defects (Keith, Rowe, and Vlad, 1958).

It has been reported to be the second most common cause of death in children suffering from heart disease (Zacharioudakis, Terplan and Lambert, 1957). An accurate appraisal of the life-span of a child born with a ventricular septal defect is difficult to secure. Death in the first year of life from an isolated ventricular septal defect is not uncommon. If an infant survives the first year of life without developing heart failure, or with proper medical management of heart failure, life expectancy should depend upon the size of the defect, the volume of flow through it and the pulmonary resistance. As pulmonary vascular resistance increases, the volume of shunt diminishes and the child may lead a relatively asymptomatic life until such a time as the shunt becomes bi-directional or from right to left and the patient succumbs in early adult life. In a series of 98 catheter-proven ventricular septal defects in children, Fyler, Rudolph, Wittenborg and Nadas (1958) found only one death after infancy. There were five deaths in infancy in this study.

\section{Pathological Anatomy}

The defect in the ventricular septum is usually in the region of the membranous portion, more accurately defined as the area between the papillary muscle of the conus and the crista supraventricularis of the right ventricle. The defects are not restricted to this membranous

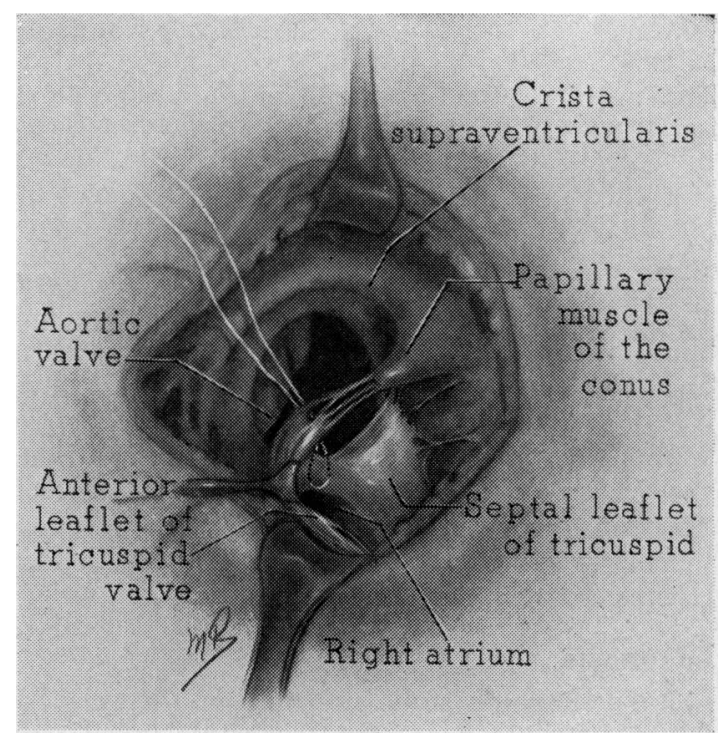

FIG. 1.-The classical ventricular septal defect in the membranous portion of the septum. We have found a key suture placed through the annulus of the septal leaflet of the tricuspid valve from the right atrium to be very useful. If this suture is accurately placed, tension on it will demonstrate the inferior margin of the defect and the course of the bundle of His defined.

portion of the septum. In those instances where the defect is above the crista supraventricularis or in the muscular portion of the septum, the rim usually consists of smooth muscle tissue and is circular in outline. When the defect is in the membranous portion of the septum, the shape is usually oval and the superior margin may extend to the aortic valve ring. The inferior margin is most variable, partly muscular and partly fibrous, and is limited by the papillary muscle of the conus (Fig. I). When the defect is small, I cm. or less, there may be a well-defined fibrous margin between the septal leaf of the tricuspid valve and the aortic leaf of the mitral valve. However, when the defect is large, the septal 


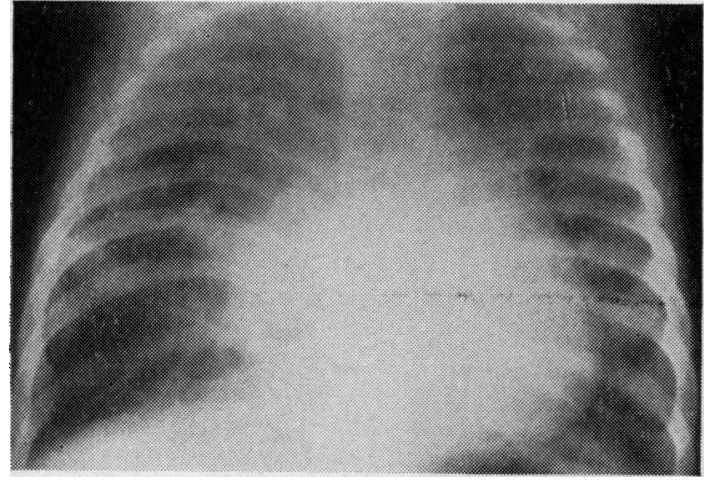

FIG. 2.-The plain radiograph of an infant of four months with catheter-proven isolated ventricular septal defect. The heart is enlarged and the lung fields show increased vascular marking.

leaf of the tricuspid valve occludes the lower third of the defect and the margin then becomes the junction of the aortic leaf of the mitral valve and the septal leaf of the tricuspid valve. There is occasionally a white fibrous area on the wall of the right ventricular myocardium opposite the jet stream of the ventricular septal defect. Spontaneous closure has been reported even in defects which were considered large in infancy (Evans, Rowe and Keith, 1960).

\section{Diagnosis}

A harsh pan-systolic murmur in the third or fourth left interspace with a palpable thrill in an acyanotic child is almost pathognomonic of ventricular septal defect. In infants with pulmonary hypertension, dyspnœa may be present at rest but in older children exercise tolerance is remarkable and many lead a normal, active life. In the infant a classical murmur is present with a history of failure to thrive and repeated respiratory infections. Cardiac enlargement is present with increased hilar vascular markings (Fig. 2) and the electrocardiogram may demonstrate right or combined ventricular hypertrophy. In the older child exercise tolerance may be normal or only slightly limited. However, in appearance, our group of operated patients were usually thin, poorly developed children with a bulging precordium. If the defect is moderate or large, a thrust is present over the apex of the heart accompanied by a coarse thrill. On radiological examination the heart may be normal in size but is usually enlarged, particularly the left atrium, with bulging pulmonary artery, increased hilar shadows and hilar pulsations. We consider a plain radiograph to be of considerable surgical significance, and increased vascular markings well

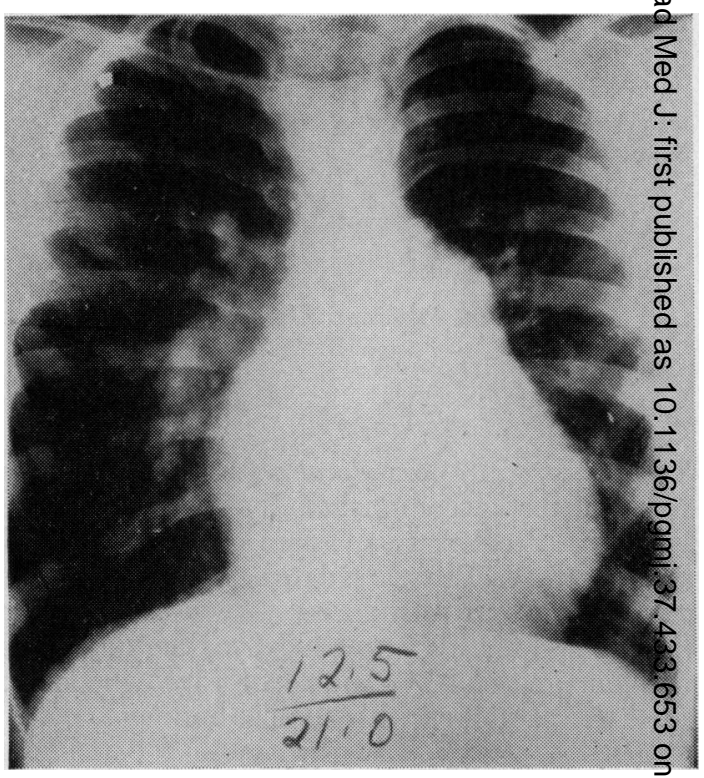

FIG. 3.-The radiograph of a child age ro years with a catheter-proven ventricular septal defect. \$he heart is enlarged and the lungs plethoric. Despite systemic pressure in the right ventricle, the defect was closed successfully.

out into the periphery even in the presence of $\frac{0}{2} \frac{\mathbb{S}}{4}$ monary hypertension, indicates increased rather than increased resistance (Fig. 3). In the older child the electrocardiogram may be nor 鱼al or show left "ventricular hypertrophy, combiped hypertrophy or a moderate degree of right hypertrophy. The axis is usually in the normal rarge. Right axis deviation is present in cases wifth severe pulmonary hypertension. Cardiac catheterization, although not as useful in the infant as]in the older child, usually confirms the diagnosis may demonstrate an additional lesion such as a patent ductus arteriosus. Selective angiocardiography may reveal recirculation of the conthast medium through the defect. Occasionally the defect may be outlined and an indication of size obtained.

\section{Estimation of Pulmonary Blood Flow} 윽

On physical examination children with a läge pulmonary blood flow will demonstrate an ogeractive heart with a good systolic murmur and thrill and occasionally an inflow diastolic murrgur at the apex. Children with a low flow and Gncreased pulmonary vascular resistance usuilly have a soft murmur and no thrill. On Xeay examination DuShane, Brandenburg, Wood Kirklin (1956) have pointed out that in patients with a large flow the left ventricle is enlarged, the right ventricle dilated, and enlarged pulmonity 


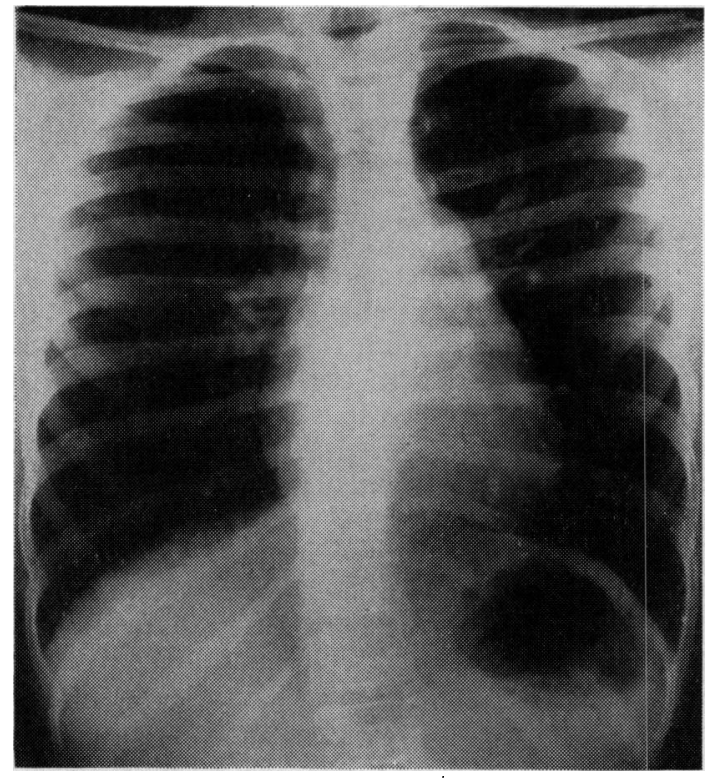

FIG. 4.-The radiograph of a 14-year-old girl with a catheter-proven isolated ventricular septal defect. The heart is small and the lung fields are clear. Systemic pressure was present in the pulmonary artery and the child was considered unsuitable for surgery.

artery shadowing seen well out into the lung fields (Fig. 3). In children with a small flow, the left ventricle is not enlarged, the right ventricle not dilated and the lung fields are clear (Fig. 4).

\section{Associated Defects}

A combination of ventricular septal defect and patent ductus arteriosus may be a cause of failure in infancy. The volume of flow through the ductus may be as great as that through the ventricular septal defect. Cardiac catheterization is very useful, particularly if the catheter is passed through the ductus and into the aorta. Ventricular septal defect associated with aortic insufficiency although rare, is sometimes difficult to distinguish from a ventricular septal defect associated with patent ductus arteriosus. Left heart catheterization may be necessary to prove the diagnosis and occasionally the diagnosis can only be made at operation. Isolated atrial secundum defect with a ventricular septal defect can be proved by cardiac catheterization. Ventricular septal defect combined with coarctation of the aorta is not uncommon; absent femoral pulses or a difference in the blood pressure in the arm and leg is helpful to aid in diagnosis.

Children with tetralogy of Fallot with normal oximetry may be difficult to distinguish on clinical examination. Cardiac catheterization with a marked pressure differential on passing through the pulmonary valve makes the diagnosis more certain.

\section{Indications for Operation}

Under One Year of Age. At the time of writing most surgeons familiar with the use of extra-corporeal circulation feel that infants tolerate the heart-lung machine poorly. For this reason, these cases should be treated medically until the initial flooding of the lung has passed. During this period banding of the pulmonary artery as has been suggested by Muller and Dammann (1952) and reported by Sirak, Hosier and Clatworthy (1959) may be a temporary measure to tide these infants over until the optimum age for extra-corporeal circulation is reached. However, in the near future an operative heart-lung machine to fill the requirements of an infant may be developed, allowing these infants to be operated upon at a young age, as has recently been demonstrated by Kirklin, McGoon and DuShane (1960).

Over One Year of Age. In the selection of patients for operation over the age of one year, one must be guided by the clinical course and by certain definitive signs. If a child is asymptomatic and has the classical murmur of a ventricular septal defect, operation may be deferred for some years. If, however, the child has an enlarging heart, operation becomes imperative. We have been guided by the use of the X-ray, the electrocardiogram, and cardiac catheterization. If a large difference in oxygen saturation between the right atrium and right ventricle is present with increased lung vascularity, the child should be operated upon at any time over one year of age. If the pulmonary artery pressure is more than $70 \%$ of the systemic pressure, operation becomes imperative. If, however, the child is clinically well, the increase in oxygen saturation between the right atrium and the right ventricle is not large, and the lungs do not show gross plethora, operation may be deferred for some years. In our clinic we have come to recognize that the child with a ventricular septal defect proven by catheterization, demonstrating enlargement of the heart and deepening of the $Q$ waves in lead $V_{6}$ of the electrocardiogram, should be operated upon before the age of six. The development of pulmonary hypertension is always a threat to these children and, although we operate upon children with identical pressures in right and left ventricles, this always presents some hazard in the post-operative period. Over the course of time the age for elective operation will become more definitive, as it has in other defects, and the inoperability of a patient will become more defined. At the present time we feel that children with a shunt from right to left should be considered inoperable. The mortality rate of un- 
complicated ventricular septal defects in childhood should be quite low in the hands of experienced surgeons, somewhere in the neighbourhood of 2 to $5 \%$ (Kay, 1960; Kirklin, McGoon and DuShane, 1960). A natural rise in operative mortality can be expected in defects complicated by other lesions and by pulmonary hypertension.

\section{Technique of Operation}

The use of the artificial heart-lung apparatus is mandatory at the present time for the closure of ventricular septal defects because of the length of time the heart is out of circulation. As confidence in the pump has increased and surgeons' experience has been gained, longer time is taken to close ventricular septal defects than in the original group of cases. Although we have done several through the right atrium, the child's right atrium is rather small and our preference is to close these defects through a right ventriculotomy in the child whose myocardium is not impaired. The incision should be kept high in the right ventricle in order to cause less of a scar in the body of that ventricle and any coronary vessels should be avoided. Occasionally an aberrant left coronary may make right atriotomy obligatory but we have not encountered this situation.

If a patent ductus is present, it must be ligated before going on the pump and this may be done either through the split sternal approach or if the diagnosis is definite, through a left thoracotomy, crossing over to the right side but not entering the pleural cavity. A left superior vena cava should be tourniqueted before going on the pump. The defect is identified and the competence of the aortic valves inspected; even if there is a slight leak through the aortic valves due to manipulation, we feel it is wise to identify the position of the valves accurately before occluding the aorta even for short periods because of the danger of placing a stitch through the aortic valve. As experience has been gained, the method of closure in each surgeon's hands becomes more definitive. Our preference is for the use of double-ended oo silk sutures reinforced with an Ivalon pledget where necessary, if the rim is muscular, and always avoiding the left side at the inferior margin of the rim to lessen the likelihood of heart block. We find that we are using a Teflon patch in more cases than doing direct suture and this may be because the defects that we are operating upon are reasonably large. In the membranous septal defect we feel that the key suture in the right inferior portion should be placed from the atrial side, in the annulus of the tricuspid valve (Fig. I). When the defect is closed it is wise to have the heart beating to allow left-sided decompression. It has not been our custom to decompress the left side of the heart since the heart is beating well when come plete closure is effected. In our earlier case acetylcholine or potassium arrest was used, but wee have abandoned this in favour of short periods of aortic occlusion with anoxic arrest.

\section{Ventricular-Atrial Septal Defect}

We have encountered two cases in which the defect in the membranous portion of the septum entered the right atrium through the base of thos tricuspid valve. These cases pose a problem if diagnosis and may be thought to be a ventricular septal defect and atrial septal defect because of the्E rise in oxygen saturation. However, the diagnos should be suspected on the basis of an appareat atrial septal defect with the clinical findings of ventricular septal defect. In one of our cases a jew was present in the atrium and the defect was repaired very easily through a right atriotomes in the second case the jet was not really looke for and a right ventriculotomy revealed a verú tricular-atrial septal defect which was closed through the right ventricle.

\section{Ventricular Septal Defect Associated with Other Defects}

Patent Ductus Arteriosus. It is obvious that the patent ductus arteriosus must be dealt with begre any extra-corporeal circulation is feasible, ot wise, when the heart is open, one is faced wita tremendous flow into the field. The surgice management has been mentioned above. In ou clinic 13 infants under one year of age with cons bined ventricular septal defect and patent ductios arteriosus have had the ductus only closed with nine survivors.

Multiple Ventricular Septal Defects. One shou国 suspect another muscular defect or multip臨 defects when the ventricular septal defect has be closed and red blood continues to well into tree right ventricle through the septum (and not from the pulmonary artery).

Aortic Insufficiency. If this diagnosis is not made pre-operatively it becomes obvious after riggt ventriculotomy. Blood from the pump oxygenator passes through the defect because of the if competent aortic valve. If the aortic valve slightly incompetent, closure of the defect alom may reduce the incompetence to an acceptabje level. However, if the aortic valve is grossly in competent, it will not do so, and this proved to se the case in one of our children who died posta operatively because of aortic incompetence follow ing successful closure of a ventricular septal defeg. If the diagnosis is suspected or made befoge operation, it is wise to enter the aorta first, repair the aortic incompetence by bicuspidization of the redundant cusp, and then, when the right vegs 
tricle is opened without aortic occlusion, the aortic valves can be inspected for competency. We have had four such cases. One of them died as a result of failure to repair the aortic incompetency. The other three had the aortic valve repaired and one died. Two are now well and have slight signs of aortic incompetency.

Atrial Septal Defect. The atrial septal defect is of the secundum type and closure is effected with a running suture. If the right atriotomy is left open and the ventricular septal defect then closed, both right ventriculotomy and atriotomy can be closed at the same time.

Severe Pulmonary Hypertension. The right ventriculotomy, particularly if it is of any extent, may lessen the function of the right ventricle in patients who have pulmonary hypertension. Exposure through the right atrium may be difficult in children whose tricuspid valves are normal and the right atrium small. However, if tricuspid incompetence is present or if the atrium is large enough, adequate exposure of the ventricular septal defect can be obtained through the atrium. We have employed this approach on a number of occasions and have found it very satisfactory. One may retract the septal leaf of the tricuspid valve or divide it to expose the defect. Another alternative is to divide the valve along the annulus and reflect the septal leaflet of the valve. Repair through the right atrium is more difficult than through the right ventricle, but the immediate post-operative course is less hazardous in a patient who has already pulmonary hypertension and a failing right ventricle. However, we have also found a ventricular septal defect in the muscular portion of the septum which we were unable to see and identify through a right atrial approach. Controversy still exists as to the proper approach in cases of pulmonary hypertension. An advantage of the atriotomy is inspection of the tricuspid valve for incompetence. The question of fenestration of a patch to allow an escape-valve mechanism in these cases remains unanswered. The tendency of most surgeons in this field is toward complete closure of the defect.

\section{Heart Block}

The most serious complication is heart block. A comprehensive survey of this has been recently published by Lauer, Ongley, DuShane and Kirklin (1960). Of 48 patients who developed heart block, 18 died in hospital. Twelve were discharged with complete heart block and four of these died subsequently. The standard treatment at the present time is the use of the pacemaker and some form of electrode in the myocardium (Weirich, Gott and Lillehei, 1958). However, the treatment of heart block is in its prevention, and a knowledge of the pathway of the bundle of His with careful monitoring during the closure of the defect is essential. For this reason we prefer not to use arrest except short periods of anoxic arrest to enable the pathological anatomy to be visualized. Our preference is to lower the body temperature with the use of a heat exchanger (Brown, Smith, Young and Sealy, 1958) and to reduce the flow rate to allow the defect to be seen more clearly.

\section{Right Ventricular Failure}

Prolonged cardiac arrest produces myocardial necrosis, arrest induced by potassium citrate resulting in the greatest damage (Willman, Cooper, Zafiracopoulos and Hanlon, I959; McFarland, Thomas, Gilbert and Morrow, 1960). Short periods of anoxic arrest will reduce the damage to the myocardium reflected in the post-operative period by right heart failure. A short, high right ventriculotomy will lessen the splinting effect of a long incision in the wall of the right ventricle. In cases of pulmonary hypertension, operation through the right atrium may be of some value in preventing right ventricular failure. Tricuspid incompetence, if recognized, should be dealt with at the same time as the ventricular septal defect is closed. Supportive measures such as the use of tracheostomy and a ventilator may be life-saving.

\section{Recurrence}

We feel that recurrence of the ventricular septal defect (as in the treatment of patent ductus arteriosus by suture ligation) develops at the time of operation from improperly placed sutures. Closure of the defect by direct sutures under too much tension will inevitably cause one or more to pull out. The same situation applies when a prosthesis is used and the sutures are placed improperly or too shallow or not buttressed by some prosthetic material in muscular rims.

\section{Summary}

Ventricular septal defect is the commonest lesion encountered in congenital heart disease in children. The natural history of the defect is still somewhat obscure. Spontaneous closure has been reported. There is strong evidence to support the fact that pulmonary hypertension does not develop necessarily unless it is already present in childhood. These facts tend to confuse the indications for operation. However, in children with large defects and enlarged hearts with a high flow to the' lungs, operation does appear to be indicated. In the infant who fails to thrive or whose failure cannot be relieved by a proper medical regime some form of operation should be attempted. Diminishing the flow to the lungs by banding the pulmonary artery, while appearing to be a simple 
procedure, may not be so simple to correct later on. It is possible that with the development of better heart-lung machines these defects should be closed directly, even in the first year of life.

The mortality rate of uncomplicated ventricular septal defects in childhood should be about 2 to $5 \%$. In defects complicated by other lesions a natural rise in operative mortality can be expected.
When the flow is balanced or bi-directional, as result of pulmonary hypertension, the mortalit 1 rises to about $25 \%$. The post-operative recurerence rate and the incidence of heart block will become lower with increasing experience.

All in all, the picture for operative correction of ventricular septal defects in childhood is quit encouraging.

\section{REFERENCES}

Abbort, M. E. (1932): Congenital Heart Disease, Nelson's Loose-Leaf Medicine, 4, 207.

Brown, Ivan W., Smith, W. W., Young, W. A., and Sealy, W. C. (1958): Experimental and Clinical Studies of Controlled Hypothermia Rapidly Produced and Corrected by a Blood Heat Exchanger During Extracorporeqt Circulation, $\mathcal{F}$. thorac. Surg., 36, 497.

DuShane, J. W., Brandenburg, R. O., Wood, E. H., and Kirklin, J. W. (1956): Criteria for Selection of Patientg with Ventricular Septal Defects for Surgical Repair, Circulation, 14, 929.

Evans, J. R., Rowe, R. D., and KeITH, J. D. (1960): Spontaneous Closure of Ventricular Septal Defects, Ibid., 22, r044.

Fyler, D. C., RudolPh, A. M., WitTEnborg, M. H., and NadAS, A. S. (1958): Ventricular Septal Defect in Infants andu Children. A Correlation of Clinical, Physiologic and Autopsy Data, Ibid., r8, 833 .

KAY, E. B. (1960): Discussion of paper by Kirklin, J. W., McGoon, D. C., and Dishan , J. W., F. thorac. Surg t્屯 40, 799.

Keith, J. D., Rowe, R. D., and VlaD, P. (1958): 'Heart Disease in Infancy and Childhood'. New York: Macmillan. O্

KIRKLIN, J. W. (1960): Surgical Correction of Ventricular Septal Defects in Infants. Paper read at American Academf of Pediatrics Meeting, October 1960, Chicago.

—, McGoon, D. C., and DuShane, J. W. (1960): Surgical Treatment of Ventricular Septal Defects, F. thorac. Surg. 40, 763 .

Lauer, R. M., Ongley, P. A., DuShane, J. W., and Kirklin, J. W. (ig60): Heart Block After Repair of Ventriculą Septal Defect in Children, Circulation, 22, 526.

Lillehei, C. W., Cohen, M., Warden, H. E., ZIEgler, N. R., and Varco, R. L. (1955): The Results of Direct Visio Closure of Ventricular Septal Defects in Eight Patients by Means of Controlled Cross Circulation, Surg. Gyne Obstet., ror, 447 .

Muller, W. H., JR., and DammanN, J. F., JR. (1952): The Treatment of Certain Congenital Malformations of $\overrightarrow{6 h} \overrightarrow{0}$ Heart by the Creation of Pulmonic Stenosis to Reduce Pulmonic Hypertension and Excessive Pulmonary Blog Flow, Ibid., 95, 213.

McFarland, J. A., Thomas, L. B., Gilbert, J. W., and Morrow, A. G. (1960): Myocardial Necrosis Following Elective Cardiac Arrest Induced with Potassium Citrate, $\mathcal{F}$. thorac. Surg., 40, 200.

Roger, H. (1879): Recherches cliniques sur la communication congenitale des deux cœurs, par inocslusion du septuri interventriculaire, Bull Acad. Méd. (Paris), 8, 1074, I 189.

Sirak, H. D., Hosier, D. M., and Clatworthy, H. W. (1959): Interventricular Septal Defects in Infancy. A Twő stage Approach to its Surgical Correction, New Engl. F. Med., 260, 147.

Weirich, W. L., GotT, V. L., and Lilleari, C. W. (I958): Treatment of Complete Heart Block by Combined Use of

Myocardial Electrode and Artificial Pacemaker, Surg. Forum, 8, 360.
Willman, V. L., Cooper, T., Zafiracopoulos, P., and Hanlon, C. R. (1 959): Depression of Ventricular Function Following Elective Cardiac Arrest with Potassium Citrate, Surgery, 46, 792.

Zacharioudakis, S. C., Terplan, K., and Lambert, E. C. (1957): Ventricular Septal Defects in the Infant Age Group Circulation, 16, 374 . 